\title{
The effect of Bulgarian propolis against Trypanosoma cruzi and during its interaction with host cells
}

\author{
Andréia Pires Dantas, Kelly Salomão, Helene Santos Barbosa*, \\ Solange Lisboa De Castro/ ${ }^{+}$
}

\begin{abstract}
Laboratório de Biologia Celular *Laboratório de Biologia Estrutural, Departamento de Ultra-estrutura e Biologia Celular, Instituto Oswaldo Cruz-Fiocruz, Av. Brasil 4365, 21040-900 Rio de Janeiro, RJ, Brasil
\end{abstract}

Propolis has shown activity against pathogenic microorganisms that cause diseases in humans and animals. The ethanol (Et-Blg) and acetone (Ket-Blg) extracts from a Bulgarian propolis, with known chemical compositions, presented similar activity against tissue culture-derived amastigotes. The treatment of Trypanosoma cruzi-infected skeletal muscle cells with Et-Blg led to a decrease of infection and of the intracellular proliferation of amastigotes, while damage to the host cell was observed only at concentration 12.5 times higher than those affecting the parasite. Ultrastructural analysis of the effect of both extracts in epimastigotes revealed that the main targets were the mitochondrion and reservosomes. Et-Blg also affected the mitochondrion-kinetoplast complex in trypomastigotes, offering a potential target for chemotherapeutic agents.

Key words: propolis - natural products - Trypanosoma cruzi - Chagas disease

Chagas disease, caused by the trypanosomatid protozoan Trypanosoma cruzi, is endemic in Latin America. Initially restricted to natural ecotopes, with transmission among small autochthonous mammals by hematophagous Triatominae bugs, the occupation by humans of such ecotopes led to the establishment of the vectors in human dwellings, changing the characteristic of the disease from zoonotic to antropozoonotic. In humans, the acute phase results in 2-8\% mortality, specially among children, while in the chronic phase most patients remain asymptomatic and about 30 to $40 \%$ of the cases develop symptoms of cardiac or digestive lesions. The World Health Organization estimates that about 18 million people are infected with T. cruzi (WHO 2002). The available drugs for the clinical treatment, the nitroderivatives benznidazole and nifurtimox, are unsatisfactory. They present variable healing effects during the acute phase according to the geographical region and require long term treatment, besides presenting frequent toxic side effects and limited efficacy in the chronic stage (reviewed in Coura \& De Castro 2001).

In this context, there is an intense search for new synthetic compounds and natural products for treatment of Chagas disease. Thus, our group has been engaged in experimental chemotherapy studies using propolis (Higashi \& De Castro 1994, De Castro \& Higashi 1995, Marcucci et al. 2001, Prytzyk et al. 2003, Paulino et al. 2003, Salomão et al. 2004). Propolis, a bee product collected from different plant exudates, is a complex mixture containing known bioactive constituents, such as flavonoids, phenolic acids and esters, terpenes, sesquiterpenes, aromatic aldehydes, and alcohols (Marcucci 1995).

Financial support: CNPq, Faperj, Fiocruz

${ }^{+}$Corresponding author: solange@ioc.fiocruz.br

Received 30 November 2005

Accepted 16 February 2006
In temperate zones, bud exudates from poplar trees (Populus spp.) are the main source of flavonoid-rich propolis, which are rich in flavonoids (reviewed in Bankova et al. 2000).

During the last decades, an increasing number of studies on the chemical composition, biological activity, and therapeutic uses of propolis has been published (reviewed in De Castro 2001). In recent studies with a Bulgarian propolis sample, we have characterized by high temperature high resolution gas chromatography coupled to mass spectrometry (HT-HRGC-MS) the composition of ethanol and acetone extracts and assayed their activity against epimastigote and trypomastigote forms of $T$. cruzi, as well as on some species of fungi and bacteria of medical importance (Prytzyk et al. 2003, Salomão et al. 2004). In the present work we have analyzed the activity of the two extracts from this Bulgarian propolis sample against tissue culture-derived and intracellular amastigotes of $T$. cruzi, as well as ultrastructural alterations induced in epimastigote and trypomastigote forms of this parasite.

\section{MATERIALS AND METHODS}

Propolis sample and preparation of the extracts - A propolis sample was collected in Burgas (Southeast Bulgaria), being the exudates collected by bees mainly from buds of Populus nigra. The resin was cut in small pieces, and after cooling bellow $-10^{\circ} \mathrm{C}$, extracted with $70 \%$ etha$\mathrm{nol}(1: 10 \mathrm{w} / \mathrm{v})$, under agitation at room temperature for 24 $\mathrm{h}$ (Bankova et al. 1999). From $4 \mathrm{~g}$ propolis extracted with hexane $(1: 25, \mathrm{w} / \mathrm{v})$ to remove apolar components, the residue was further extracted with acetone at room temperature (Prytzyk et al. 2003). Both extracts were evaporated to dryness under vacuum at $40^{\circ} \mathrm{C}$ and stored in a desicator at $4^{\circ} \mathrm{C}$. The extracts were named Et-Blg and Ket-Blg, and obtained in a yield of 62 and $10 \%$, respectively. Stock solutions were prepared in dimethysulfoxide and diluted in phosphate buffered saline (PBS) before use. The final concentration of solvent did not exceed $1 \%$, which had no effect per se on the parasites or mammalian cells. 
Parasites and cell cultures - Assays were performed with the Y strain of T. cruzi (Silva \& Nussenszweig 1953). Epimastigote forms were maintained in LIT medium supplemented with $10 \%$ fetal calf serum (FCS) (Camargo 1964) and harvested during the exponential phase of growth. Bloodstream trypomastigotes were obtained from infected Swiss mice. Amastigotes were collected from the supernatant of trypomastigote-infected J774G-8 macrophage cultures (De Castro et al. 1987). Primary cultures of skeletal muscle cells (SKMC) were prepared as previously described (Araújo-Jorge et al. 1986). Briefly, tissues from thigh muscles of 18-day-old mouse embryos were fragmented and dissociated with $0.05 \%$ trypsin and $0.01 \%$ versene in PBS. Thereafter, the cells were ressuspended in Dulbecco's modified Eagle medium, supplemented with $10 \%$ horse serum, $5 \%$ FCS, $2 \%$ embryo chicken extract, $2.5 \mathrm{mM} \mathrm{CaCl}_{2}, 1 \mathrm{mML} L$-glutamine, and antibiotics (DMEM). SKMC were plated $\left(10^{5}\right.$ cells/well $)$ on $0.02 \%$ gelatin-coated glass coverslips in 24 -well plates and maintained at $37^{\circ} \mathrm{C}$ in 5\% $\mathrm{CO}_{2}$ atmosphere (Barbosa et al. 2000).

Antitrypanosomal activity - Tissue culture-derived amastigotes were resuspended in Dulbecco's modified Eagle medium supplemented with 10\% FCS (DMES) to a concentration of $10 \times 10^{6}$ parasites $/ \mathrm{ml}$. In 96-well plates, $100 \mu \mathrm{l}$ of the parasite suspension was added to the same volume of Et-Blg or Ket-Blg, previously prepared at twice the desired final concentrations. The extracts were assayed in the range between 4 and $250 \mu \mathrm{g} / \mathrm{ml}$. After incubation at $28^{\circ} \mathrm{C}$ for $24 \mathrm{~h}$ the number of parasites was quantified using a Neubauer chamber, and the activity of the extracts expressed as $\mathrm{IC}_{50}$ values, corresponding to the concentration that induces $50 \%$ of parasite lysis.

T. cruzi suspensions $(10 \mathrm{ml})$ were treated with Et-Blg (40 to $200 \mu \mathrm{g} / \mathrm{ml}$ ), being the assays with epimastigotes performed in LIT at $28^{\circ} \mathrm{C}$ and those with trypomastigotes in DMES at $4^{\circ} \mathrm{C}$. After $24 \mathrm{~h}$ the parasites were washed in PBS and processed for electron microscopy, as described below.

Ultrastructural analysis - For transmission electron microscopy (TEM) the parasites were fixed with $2.5 \%$ glutaraldehyde (GA), $2.5 \mathrm{mM} \mathrm{CaCl}_{2}$ and $0.1 \mathrm{M} \mathrm{Na}$-cacodylate buffer ( $\mathrm{pH}$ 7.2) for $1 \mathrm{~h}$ at $4^{\circ} \mathrm{C}$. After post-fixation for $1 \mathrm{~h}$ in a solution containing $1 \% \mathrm{OsO}_{4}, 0.8 \%$ potassium ferricyanide, and $2.5 \mathrm{mM} \mathrm{CaCl}_{2}$ in cacodylate buffer, the material was processed for routine transmission electron microscopy and observed with an Zeiss EM10C microscope (Oberkochen, Germany). For monitoring the treatment, immediately after fixation in GA, control and treated parasites were fixed in methanol, stained with Giemsa and observed by light microscopy.

For scanning electron microscopy (SEM), the parasites were adhered to $0.1 \%$ poly- $L$-lysine coated coverslips and fixed in $2.5 \% \mathrm{GA}$ in $0.1 \mathrm{M} \mathrm{Na}$-cacodylate buffer for $30 \mathrm{~min}$ at room temperature, followed by rinsing in the same buffer. After post-fixation in $1 \% \mathrm{OsO}_{4}$ for $30 \mathrm{~min}$ at room temperature, the material was dehydrated in an ascending acetone series, dried by the critical point method with $\mathrm{CO}_{2}$, mounted with silver cellotape on aluminium stubs and coated with a $20 \mathrm{~nm}$-thick layer of gold. The samples were examined with a Zeiss DSM 940 microscope.
Effect of Et-Blg on the interaction of T. cruzi with $S K M C$ - After plating for $96 \mathrm{~h}, \mathrm{SKMC}$ were infected with bloodstream trypomastigotes (at a 1:10 parasite:host cell ratio) in DMEM for $18 \mathrm{~h}$ and washed to remove non-internalized parasites. Et-Blg was added in final concentrations ranging from 3 to $12 \mu \mathrm{g} / \mathrm{ml}$ and this medium was changed every two days. After 24,48 , and $72 \mathrm{~h}$ of treatment, the cultures were fixed and processed for light microscopy and the infection levels were quantified using an Zeiss Axioplan microscope.

\section{RESULTS}

Effect of the extracts on amastigote forms of T. cruzi Both propolis extracts, Et-Blg and Ket-Blg, were active against tissue culture-derived amastigotes presenting $\mathrm{IC}_{50} / 24 \mathrm{~h}$ of $36.4 \pm 4.9 \mu \mathrm{g} / \mathrm{ml}$ and $39.5 \pm 8.2 \mu \mathrm{g} / \mathrm{ml}$, respectively (Fig. 1a). In relation to control cells, treatment of
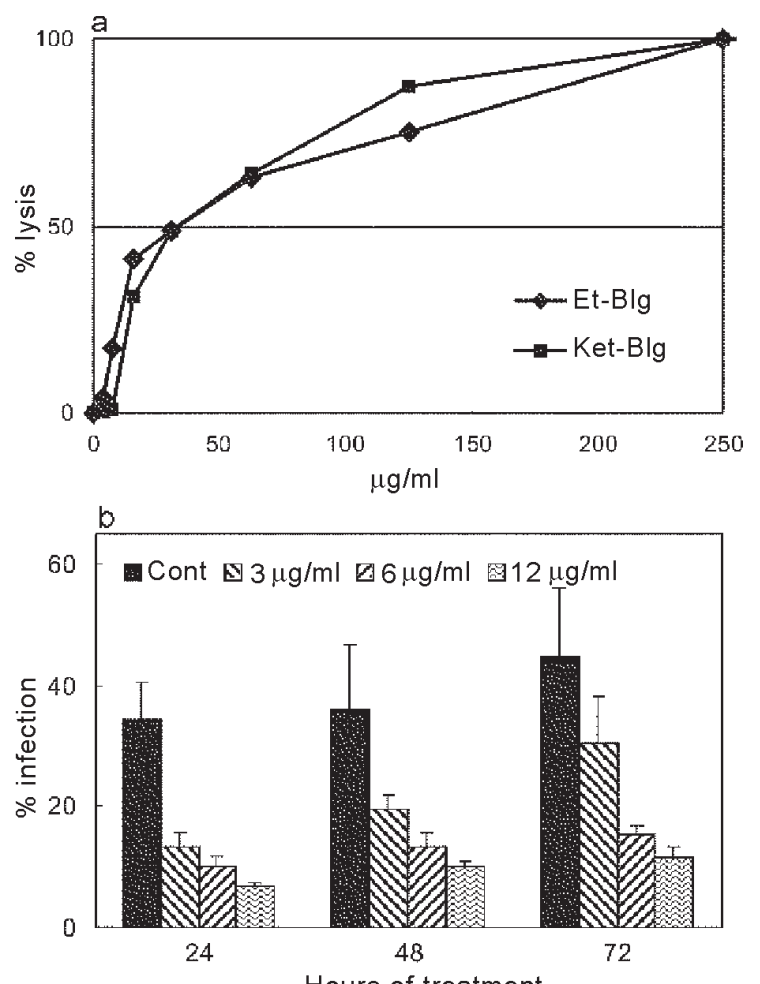

Hours of treatment

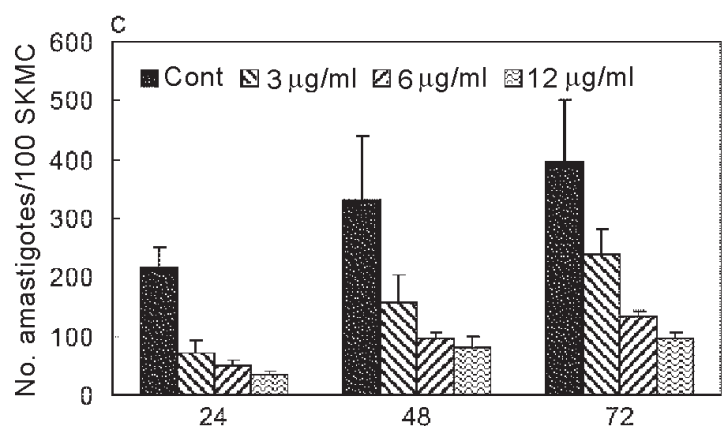

Fig. 1: effect of Et-Blg on Trypanosoma cruzi - a: culture-derived amastigotes collected from the supernatant of J-774G8 cell line; b: $\%$ infection inhibition of $T$. cruzi-infected skeletal muscle cells (control $=100 \%$ infection); $\mathrm{c}$ : percent of parasites $/ 100$ skeletal muscle cells. 
T. cruzi-infected SKMC with Et-Blg led to an increase in the percent of infection inhibition (Fig. 1b), and inhibited the proliferation of intracellular parasites with an $\mathrm{IC}_{50} / 24$ $\mathrm{h}$ of $2.2 \pm 0.3 \mu \mathrm{g} / \mathrm{ml}$ (Fig. 1c). Damage to the host cells was observed only in concentrations above $25 \mathrm{mg} / \mathrm{ml}$ (data not shown).

Ultrastructural alterations induced on T. cruzi Analysis by TEM of epimastigotes treated with $100 \mu \mathrm{g} / \mathrm{ml}$ Ket-Blg for $24 \mathrm{~h}$ showed interference on the morphology of the mitochondrion, including rarefaction of the matrix, absence of crystae in the inner membrane and increase of organelle volume (Fig. 2c). Alterations were also observed in the reservosomes, which presented a heterogeneous shape and large electron-lucent inclusions (Fig. 2c). Treatment with $80 \mu \mathrm{g} / \mathrm{ml} \mathrm{Et-Blg}$ led to alterations in the organization of the kinetoplast and the mitochondrion, to the formation of concentric membranous structures and large vacuoles in the cytoplasm, and to a decrease in electron density of reservosomes (Figs 2e-g). SEM revealed that
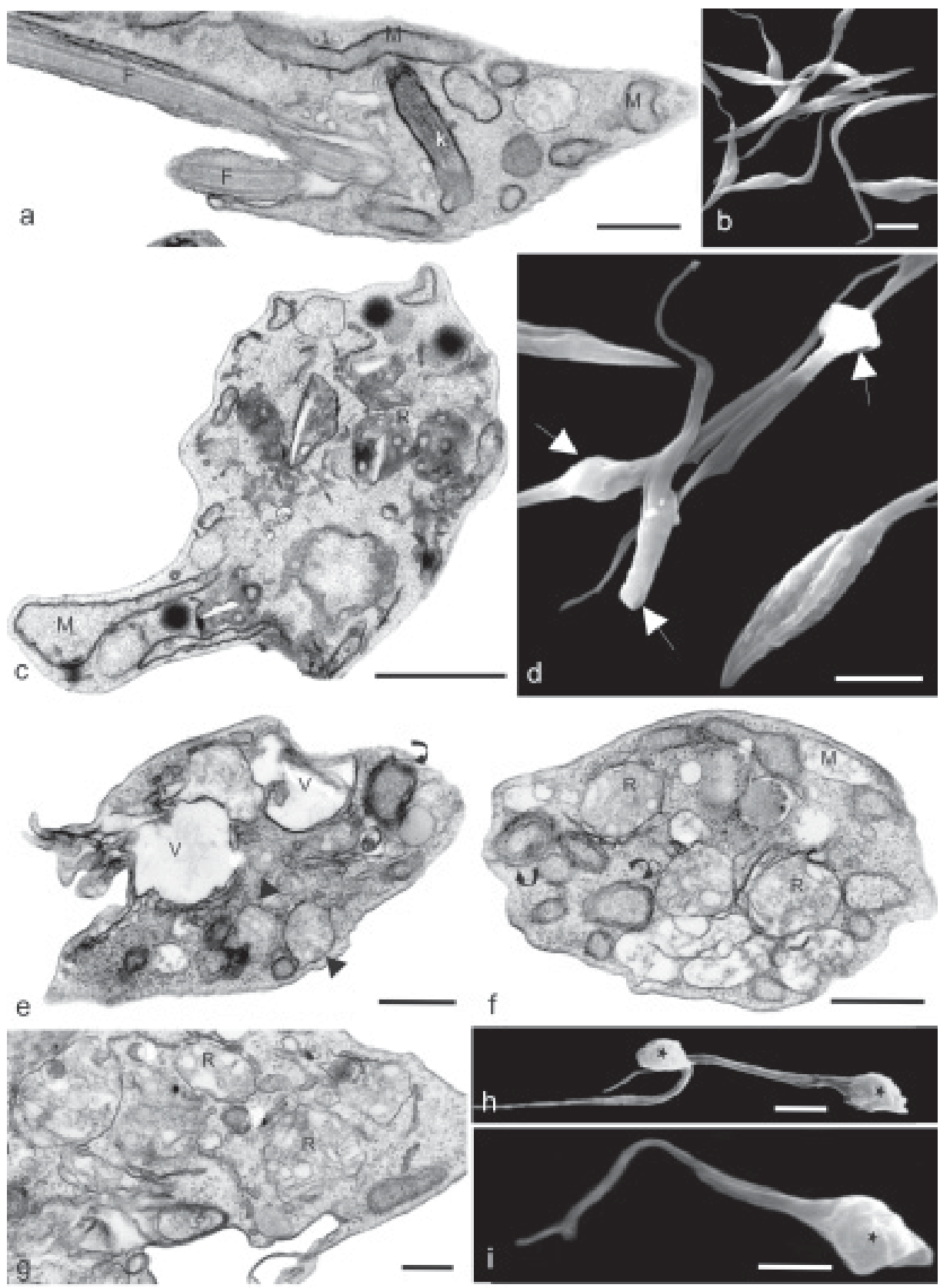

Fig. 2: ultrastructural alteration in epimastigotes of Trypanosoma cruzi treated with the propolis extracts for $24 \mathrm{~h}$ - a,b: control parasites. Note the elongated body and the normal aspect of organelles (k, kinetoplast; F, flagellum; M, mitochondrion) by transmission electron microscopy and the elongated body by scanning electron microscopy; c: $100 \mu \mathrm{g} / \mathrm{ml} \mathrm{Ket-Blg}$ led to alterations in the mitochondrion (M) and in reservosomes (R), which presented electron-lucent inclusions (*) and heterogeneous forms; d: $100 \mu \mathrm{g} / \mathrm{ml} \mathrm{Ket-Blg}$ induced an atypical morphology in the parasites (white arrows); e-g: $80 \mu \mathrm{g} / \mathrm{ml} \mathrm{Et-Blg}$ led to formation of large vacuoles (V) and concentric membrane structures (curved arrows) in the cytoplasm, decrease of the electron density of reservosomes (R) and mitochondrial alterations (M); h,i: $80 \mu \mathrm{g} / \mathrm{ml} \mathrm{Et-Blg}$ induced shortening of the parasite body (stars). Bars: $0.5 \mu \mathrm{m}$ (a); $1 \mu \mathrm{m}$ (b-d), $10 \mu \mathrm{m}(\mathrm{e}, \mathrm{f}), 2.5 \mu \mathrm{m}(\mathrm{g}), 5 \mu \mathrm{m}(\mathrm{h})$. 
Ket-Blg induced alterations in the body shape (Fig. 2d), while Et-Blg always led to rounding and shortening of the parasites (Figs 2h,i).

Trypomastigotes treated with $100 \mu \mathrm{g} / \mathrm{ml} \mathrm{Et-Blg}$ for 24 $\mathrm{h}$ presented a dilated mitochondrion with matrix rarefaction and scarcity of crystae, especially at the kinetoplast region (Fig. 3b). Increasing the concentration of the extract to $200 \mu \mathrm{g} / \mathrm{ml}$, the ultrastructural alterations were more intense, affecting a higher number of parasites (data not shown). SEM analysis of trypomastigotes treated with $100 \mu \mathrm{g} / \mathrm{ml}$ Et-Blg showed rounding of the posterior region with maintenance of the normal morphology of the flagel$\operatorname{lum}$ (Figs 3c,d).

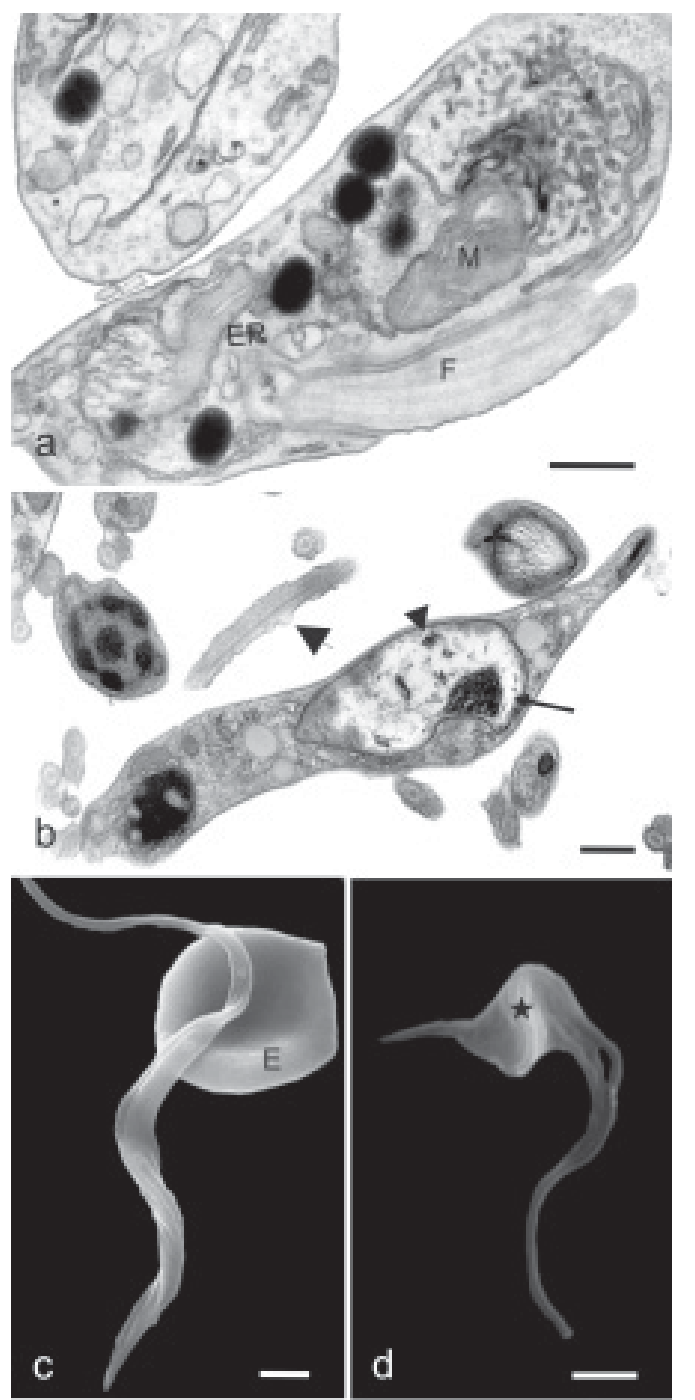

Fig. 3: ultrastructural alteration in trypomastigotes of Trypanosoma cruzi treated with Et-Blg for $24 \mathrm{~h}$ - a: control parasites. Note the characteristic morphology of the organelles, the elongated body, and the terminal flagellum (M, mitochondrion; ER, endoplasmatic reticulum; F, flagellum) by transmission electron microscopy; $\mathrm{b}$ : $100 \mu \mathrm{g} / \mathrm{ml}$ Et-Blg led to alterations in the mitochondrion (arrowhead), to an increased elecTrondensity of the kinetoplast (arrow). Eventually, blebs in the flagellum could be observed (small arrow); c: control parasite. Note the elongated body, close to an erythrocyte (E) by scanning electron microscopy; d: $100 \mu \mathrm{g} / \mathrm{ml}$ Et-Blg led to an increase of the cellular volume at the posterior region of the parasite (star). Bars $=0.125 \mu \mathrm{m}$ (a); $0.25 \mu \mathrm{m}$ (b); $1.5 \mu \mathrm{m}$ (c,d).

\section{DISCUSSION}

In the present work, we demonstrated that ethanol (Et-Blg) and ketone (Ket-Blg) propolis extracts presented similar activity against tissue culture-derived amastigotes of $T$. cruzi, with $\mathrm{IC}_{50} / 24 \mathrm{~h}$ between 36 and $40 \mu \mathrm{g} / \mathrm{ml}$. In a previous work we have observed that both extracts showed similar $\mathrm{IC}_{50}$ values against trypomastigotes (Prytzyk et al. 2003). Evaluation of the activity of Et-Blg against $T$. cruzi-infected SKMC showed that intracellular parasites were about 20 times more susceptible than tissue culture-derived forms, and their proliferation was inhibited in concentrations 12.5 times lower than those which led to damage to the host cells.

Comparison between the direct effect of Et-Blg against the three forms of the parasite showed that tissue-culture derived amastigotes were more susceptible than epimastigotes (Prytzyk et al. 2003) and trypomastigotes (Salomão et al. 2004). Such difference in susceptibility to Et-Blg among the three forms of $T$. cruzi has been already described in treatments with other drugs (Schlemper et al. 1977, De Castro et al. 1992, 1993).

Ultrastructural alterations induced by Ket-Blg and Et$\mathrm{Blg}$ in epimastigote forms were similar in several aspects, showing that the main targets were the mitochondrion and reservosomes, together with alterations in the body shape as observed by SEM. Rarefaction of the mitochondrial matrix, absence of crystae and mitochondrial swelling have been already described after treatment of the parasites with different drugs, such as inhibitors of sterol biosynthesis (Lazardi et al. 1990, Santa Rita et al. 2000, Magaraci et al. 2003) and other synthetic compounds (Bernacchi et al. 2002). The presence of heterogeneous forms and large electron-lucent inclusions in the reservosomes after treatment with Et-Blg has been already reported in the DM28 clone of $T$. cruzi, suggesting a rupture of the organelle (De Souza et al. 2002). Since reservosomes are acidic storage compartments in epimastigotes (Soares 1999), decrease in the electron-density of the matrix of these organelles in Et-Blg-treated parasites suggests a possible interference in the content of lipids and proteins.

Trypomastigotes treated with Et-Blg showing disruption of the kinetoplast structure besides mitochondrial alterations suggest that this complex, i.e. the mitochondrion-kinetoplast, is a potential target of the propolis extract.

It has been already shown propolis activity against pathogenic microorganisms that cause diseases in humans and animals (reviewed in De Castro 2001, Prytzyk et al. 2003, Salomão et al. 2004). The present work encourages further investigations on the effect of propolis in experimentally $T$. cruzi-infected mice, aiming an alternative natural product for the treatment of Chagas disease.

\section{ACKNOWLEDGMENTS}

To Dr Maurilio J Soares for the critical reading of this manuscript, and to Renata M Rodrigues for her excellent technical assistance.

\section{REFERENCES}

Araújo-Jorge TC, Barbosa HS, Moreira AL, De Souza W, 
Meirelles MNL 1986. The interaction of myotropic and macrophagotropic strains of Trypanosoma cruzi with myoblasts and fibres of skeletal muscle. Z Parasitenkd 72: 577 584.

Bankova VS, Boudourova-Krasteva G, Sforcin JM, Frete X, Kujumgiev A, Maimoni-Rodella R, Popov S 1999. Phytochemical evidence for the plant origin of Brazilian propolis from São Paulo state. Z Naturforsch 54C: 401-405.

Bankova VS, De Castro SL, Marcucci MC 2000. Propolis: recent advances in research on chemistry and plant origin. Apidologie 31: 3-15.

Barbosa HS, Pereira MCS, Meirelles MNL 2000. Protocolos de culturas primárias. In TC Araújo-Jorge, SL de Castro (eds), Doença de Chagas: Manual para Experimentação Animal, Fiocruz, Rio de Janeiro, p. 297-313.

Bernacchi AS, Franke de Cazzulo B, Castro JA, Cazzulo JJ 2002. Trypanocidal action of 2,4-dichloro-6-phenylphenoxyethyl diethylamine hydrobromide (Lilly 18947) on Trypanosoma cruzi. Acta Pharmacol Sin 23: 399-404.

Camargo EC 1964. Growth and differentiation in Trypanosoma cruzi. Origin of metacyclic trypanosomes in liquid media. Rev Inst Med Trop São Paulo 6: 93-100.

Coura JR, De Castro SL 2001. A critical review on Chagas disease chemotherapy. Mem Inst Oswaldo Cruz 91: 3-24.

De Castro SL 2001. Propolis: biological and pharmacological activities. Therapeutic uses of this bee-product. Ann Rev Biol Sci 3: 49-83.

De Castro SL, Higashi K 1995. Effect of different formulations of propolis on mice infected with Trypanosoma cruzi. $J$ Ethnopharmacol 46: 55-58.

De Castro SL, Meirelles MNL, Oliveira MM 1987. Trypanosoma cruzi: adrenergic modulation of cAMP role in proliferation and differentiation of amastigotes in vitro. Exp Parasitol 64: 368-375.

De Castro SL, Soeiro MNC, Higashi KO, Meirelles MNL 1993. Differential effect of amphotericin B on the three evolutive stages of Trypanosoma cruzi and on the host cell-parasite interaction. Braz J Med Biol Res 26: 1219-1229.

De Castro SL, Soeiro MNC, Meirelles MNL 1992. Trypanosoma cruzi: effect of phenothiazines on the parasite and on its interaction with host cells. Mem Inst Oswaldo Cruz 87: 209-215.

De Souza W 2002. From the cell biology to the development of new chemotherapeutic approaches against trypanosomatids: dreams and reality. Kinetoplastid Biology and Disease 1: 3-24.

Higashi KO, De Castro SL 1994. Propolis extracts are effective against Trypanosoma cruzi and have an impact on its inter- action with host cells. J Ethnopharmacol 43: 149-155.

Lazardi K, Urbina JA, De Souza W 1990. Ultrastructural alterations induced by two ergosterol biosynthesis inhibitors, ketoconazole and terbinafine, on epimastigotes and amastigotes of Trypanosoma (Schizotrypanum) cruzi. Antimicrob Agents Chemother 34: 2097-2105.

Magaraci F, Jimenez CJ, Rodrigues C. Rodrigues JCF, Braga MV, Yardley V, de Luca Fradley K, Croft SL, De Souza W, Ruiz Perez LM, Urbina JA, Pacanowska DG, Gilbert IH 2003. Azasterols as inhibitors of sterol 24-methyltransferase in Leishmania species and Trypanosoma cruzi.J Med Chem 46: 4714-4727.

Marcucci MC 1995. Propolis: chemical composition, biological properties and therapeutic activity. Apidologie 26: 8399.

Marcucci MC, Ferreres F, Garcia-Viguera C, Bankova VS, De Castro SL, Dantas AP, Valente PH, Paulino N 2001. Phenolic compounds from Brazilian propolis with pharmacological activities. J Ethnopharmacol 74: 105-112.

Paulino N, Dantas AP, Bankova VS, Longhi DT, Scremin A, De Castro SL, Calixto JB 2003. Bulgarian propolis induces analgesic and anti-inflammatory effects in mice and inhibits in vitro contraction of airway smooth muscle. J Pharmacol Sci 93: 307-313.

Prytzyk E, Dantas AP, Salomão K, De Castro SL, Aquino-Neto FR, Bankova VS, Pereira AS 2003. Flavonoids and trypanocidal activity of Bulgarian propolis. J Ethnopharmacol 88: 189-193.

Salomão K, Dantas AP, Campos LC, Borba CM, Machado DG, Aquino-Neto FR, De Castro SL 2004. Chemical composition and biological activity of extracts from Brazilian and Bulgarian propolis. Lett Appl Microbiol 38: 87-92.

Santa-Rita RM, Barbosa HS, Meirelles MNL, De Castro SL 2000. Effect of alkyllysophospholipids on the proliferation and differentiation of Trypanosoma cruzi. Acta Trop 75: 219-228.

Schlemper BR, Chiari E, Brener Z 1977. Growth inhibition drug test with Trypanosoma cruzi culture forms. J Protozool 24: 544-547.

Silva LHP, Nussenszweig V 1953. Sobre uma cepa de Trypanosoma cruzi virulenta para o camundongo branco. Folia Clin Biol 20: 191-207.

Soares MJ 1999. The reservosome of Trypanosoma cruzi epimastigotes: an organelle of the endocytic pathway with a role on metacyclogenesis. Mem Inst Oswaldo Cruz 94: 139-141.

WHO-World Health Organization 2002. Control of Chagas Disease. Technical Reports Series 905: 1-109. 